\title{
Article
}

\section{The primary corrosiveness of crude oils and destructions of metals}

\author{
Suresh Aluvihara ${ }^{1, *}$ and Jagath K. Premachandra ${ }^{2}$ \\ 1 Department of Chemical and Process Engineering, University of Peradeniya, Peradeniya, Sri Lanka. \\ 2 Department of Chemical and Process Engineering, University of Moratuwa, Katubedda, Sri Lanka. \\ * Correspondence: sureshaluvihare@gmail.com
}

Received: 25 August 2019; Accepted: 1 October 2019; Published: 19 October 2019.

\begin{abstract}
Metals play predominant prefaces regarding most of industrial components such as the crude oil refining industry although corrosion performed some banes. In the current research it was expected to investigate to compare the effect of corrosive properties of two different crude oils on the rates of corrosion in seven different types of ferrous metals. The contents of sulfur, mercaptans, organic acids, salt in both crude oils and chemical compositions of ferrous metals were determined by standard methods and instruments. A batch of similar sized metal coupons was prepared and immersed in both crude oils separately. The corrosion rate of each metal coupon was determined by the weight loss method in order to after 15, 30 and 45 days while observing the corroded metal surfaces by the optical microscope. The decayed concentrations of copper and ferrous in each crude oil sample were tested and the both initial and final hardness of each metal coupon were tested. According to the results there were observed lower corrosion rates from stainless steels, relatively higher impact from salts on the corrosion, formation corrosion compounds, corrosion cracks, pitting corrosion on metal surfaces and there were observed a slight reduction of hardness in each metal coupon eventually.
\end{abstract}

Keywords: Ferrous metals, crude oils, corrosion rate, corrosive properties, hardness.

\section{Introduction}

C orrosion is a common term germane the industry of crude oil refining similarly generate a few of problems on such ferrous metals. Upon the hole the corrosion is the formation of metal oxides, sulfides, hydroxides or other certain compound on the surface of such a metal yet the rate of corrosion is depend on the conditions of the surrounding and chemical composition of such metal as well [1]. As an essential requirement of the corrosion the metal need to be exposed either some kind of stronger oxidizing agent than $\mathrm{Fe}_{2}+$ or any environment consisting water and oxygen also the process will be modified by the acids and salt present in the medium. Beside of that the mercaptans and elemental sulfur play a dominant role in the cause of metallic corrosion [2]. Those compounds are found in crude oil in various amounts. Therefore, the crude oil can be emphasized as a corrosive admixture especially in the industry of crude oil refining because of the vast applications of ferrous metals with regard to different units such as the distillation column, storage tanks and transportation tubes. In the current research there were expected to investigate the effect of different two types of crude oils on the rates of corrosion in seven different types of ferrous metals and the variations of the initial hardness of such metals due to the corrosion.

\section{Materials and methodology}

\subsection{Materials}

\subsubsection{Ferrous metals}

Seven different types of ferrous metals were selected as the samples which are having foremost applications in the industry of crude oil refining frequently. A batch of samples was consisted with three different types of carbon steels, three different types of stainless steel and Monel. 


\subsubsection{Crude oils}

It was selected two different types of crude oils which were used in the Sri Lankan crude oil refining industry and also those are slightly different in their chemical composition including essential properties such as corrosive properties.

\subsection{Methods}

\subsubsection{Experiments on crude oils}

The sulfur content, Mercaptans content, acidity and the salt content of both crude oils were determined. Because those are the dominant corrosive properties found in crude oils. A descriptive summary of the relevant procedures of experiments for such properties has been given in the Table 1 . There were determined the ferrous

Table 1. Procedures of the experiments for the corrosive properties in crude oils

\begin{tabular}{|c|c|c|}
\hline Property & Method & Readings \\
\hline Sulfur content & Directly used & Direct reading \\
\hline Acidity & $\begin{array}{c}\text { Each sample was dissolved in a mixture of } \\
\text { toluene and isopropyl and titrated with } \\
\text { potassium hydroxide. }\end{array}$ & End point \\
\hline Mercaptans content & $\begin{array}{c}\text { Each sample was dissolved in sodium acetate } \\
\text { and titrated with silver nitrate. }\end{array}$ & End point \\
\hline Salt Content & $\begin{array}{c}\text { Each sample was dissolved in organic solvent } \\
\text { and exposed to the cell analyzer. }\end{array}$ & sample \\
\hline
\end{tabular}

concentration of crude oil samples which were exposed to the carbon steels and stainless steels by the atomic absorption spectroscopy (AAS). It was also tested the copper concentrations in crude oil samples which were exposed to Monel by the same instrument because of the confirmation evidences for the corrosion eventually.

\subsubsection{Experiments on metals}

The elemental composition of each type of metal was determined by the XRF detector due to the importance of the chemical composition on the rate of corrosion. According to the working principles of the XRF detector it was able to detect the compositions of each metal and even though most of nonmetals without carbon. A batch of similar sized metal coupons was prepared from seven different types of ferrous metals. Those metal coupons were immersed homogeneously in separate crude oil samples as shown in the Figure 1.

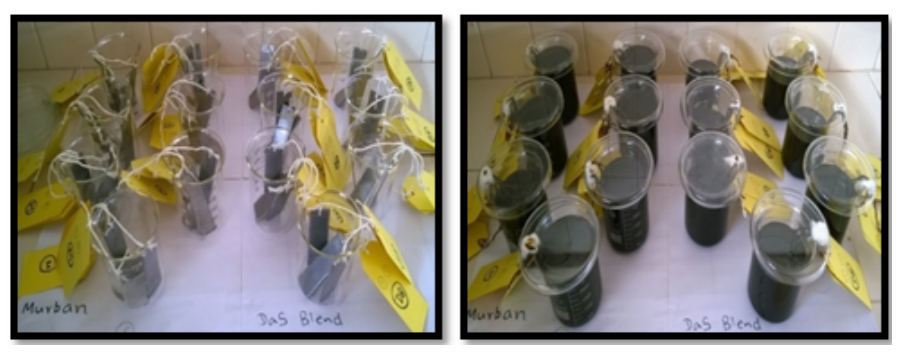

Figure 1. (a) Samples (b) Set up of apparatus

The corrosion rates of metal a batch of metal coupons were determined by the weight loss method after 15 days from the immersion at once. A batch was consisted seven types of metal and the same procedure was repeated for another two similar batches of metal coupons in order to after 30 days and 45 days from the immersion while observing the corroded surfaces through the 400X lens of an optical microscope and the corroded metal surfaces were cleaned by sand papers and isooctane. Also the initial weight and weight after removing corroded particles were measured by analytical balance as a necessity of the calculations [3]. The mathematical expression of the weight loss method is given in the Equation (1).

$$
C R=W * k /(D * A * T)
$$


Where, $W=$ weight loss in grams, $k=$ constant $(22,300), D=$ metal density in $\mathrm{g} / \mathrm{cm}^{3}, A=$ area of metal piece $\left(\right.$ inch $\left.^{2}\right), t=$ time (days), $C R=$ Corrosion rate of metal piece.

The initial hardness and the hardness after the corrosion were tested in each metal coupon by the Vicker's hardness tester eventually. According to the working principles of the Vicker's hardness tester there were tested at least three particular points on each metal coupon at once and the average value was interpreted as the hardness of the metal [4].

\section{Results and Discussion}

\subsection{Chemical Compositions of Metals}

According to the readings of XRF detector the elemental compositions of ferrous metals are given in the Table 2.

Table 2. Chemical compositions of metals

\begin{tabular}{|c|c|c|c|c|c|c|c|c|c|c|c|c|}
\hline Metal & $\begin{array}{l}\mathrm{Fe} \\
(\%)\end{array}$ & $\begin{array}{l}\text { Mn } \\
(\%)\end{array}$ & $\begin{array}{l}\text { Co } \\
(\%)\end{array}$ & $\begin{array}{l}\mathrm{Ni} \\
(\%)\end{array}$ & $\begin{array}{l}\mathrm{Cr} \\
(\%)\end{array}$ & $\begin{array}{l}\mathrm{Cn} \\
(\%)\end{array}$ & $\begin{array}{c}\mathrm{P} \\
(\%)\end{array}$ & $\begin{array}{l}\text { Mo } \\
(\%)\end{array}$ & $\begin{array}{l}\mathrm{Si} \\
(\%)\end{array}$ & $\begin{array}{c}\mathrm{S} \\
(\%)\end{array}$ & $\begin{array}{c}\mathrm{Ti} \\
(\%)\end{array}$ & $\begin{array}{c}\mathrm{V} \\
(\%)\end{array}$ \\
\hline $\begin{array}{c}\text { Carbon Steel } \\
\text { (High) }\end{array}$ & 98.60 & 0.43 & - & 0.17 & 0.14 & 0.7 & 0.12 & 0.086 & 0.09 & - & - & - \\
\hline $\begin{array}{l}\text { Carbon Steel } \\
\text { (Medium) }\end{array}$ & 99.36 & 0.39 & - & - & - & - & 0.109 & - & 0.14 & $<0.002$ & $<0.04$ & - \\
\hline $\begin{array}{c}\text { Carbon Steel } \\
\text { (Mild Steel) } \\
410-\mathrm{MN}: 1.8\end{array}$ & 99.46 & 0.54 & $<0.30$ & - & $<0.07$ & - & - & - & - & - & $<0.19$ & $<0.07$ \\
\hline $\begin{array}{c}\text { 420-MN: } 2.8 \\
\text { (Stainless Steel) }\end{array}$ & 88.25 & 0.28 & - & 0.18 & 10.92 & 0.10 & 0.16 & - & 0.11 & - & - & - \\
\hline $\begin{array}{c}\text { 410-MN: } 1.7 \\
\text { 420-MN: } 1.7 \\
\text { (Stainless Steel) }\end{array}$ & 87.44 & 0.30 & - & - & 11.99 & - & 0.18 & - & 0.09 & - & - & - \\
\hline $\begin{array}{c}\text { 321-MN: } 1.4 \\
\text { 304-MN: } 1.9 \\
\text { (Stainless Steel) }\end{array}$ & 72.47 & 1.44 & - & 8.65 & 17.14 & - & 0.18 & - & 0.12 & - & - & - \\
\hline Moneal 400 & 1.40 & 0.84 & 0.11 & 64.36 & $<0.04$ & 33.29 & - & - & - & - & - & - \\
\hline
\end{tabular}

The results showed relatively higher percentage of ferrous in carbon steels, moderate amount of ferrous in stainless steels and trace amount of ferrous in Monel metal whilst composed significant amounts of nickel and copper. Beside of that there were found some trace amounts of nickel and chromium in especially stainless steels based on the enhancements of their properties such as the hardness, stress and reduction of the corrosion rate as well $[1,2,4]$.

\subsection{Corrosive Properties of Crude Oils}

According to the quantitative analysis of the corrosive properties the numerical values for those properties of both crude oils are given in the Table 3.

Table 3. Corrosive properties of crude oils

\begin{tabular}{||ccc||}
\hline Property & Murban & Das Blend \\
\hline \hline Sulfur Content (Wt. \%) & 0.758 & 1.135 \\
Salt content (ptb) & 4.4 & 6.3 \\
Acidity (mg KOH/g) & 0.01 & 0.02 \\
Mercaptans content (ppm) & 25 & 56 \\
\hline
\end{tabular}

It was shown higher amount of organic acids in Das Blend crude oil than the Murban crude oil. Acidity is the parameter which interprets the total amount of organic acids presents in a certain crude oil also called "naphthenic acids" which is having a general formula of $\mathrm{RCOOH}$ also play a major role in the metallic corrosion 
$[2,5,6]$. In some of recent previous researches there were interpreted some relationships between the acidity and the rate of corrosion of metals. The general mechanism of the formation of the metallic corrosion is given in the Equation (2), Equation (3) and Equation (4).

$$
\begin{gathered}
\mathrm{Fe}+2 \mathrm{RCOOH} \rightarrow \mathrm{Fe}(\mathrm{RCOO})_{2}+\mathrm{H}_{2} \\
\mathrm{FeS}+2 \mathrm{RCOOH} \rightarrow \mathrm{Fe}(\mathrm{COOR})_{2}+\mathrm{H}_{2} \mathrm{~S} \\
\mathrm{FE}(\mathrm{COOR})_{2}+\mathrm{H}_{2} \mathrm{~S} \rightarrow \mathrm{FeS}+2 \mathrm{RCOOH}
\end{gathered}
$$

According to the obtained results it was found some higher amount of salts from Murban crude oil than the Das Blend crude oil. The summation of the $\mathrm{NaCl}, \mathrm{CaCl}_{2}$ and $\mathrm{MgCl}_{2}$ in a particular crude oil is known as the total salt content of that particular crude oil. At some higher temperature conditions those salts tend to be broken into $\mathrm{HCl}$ even though does not behave as corrosive compounds in the gas state [7]. When reducing the temperature some of molecules tend to be reacted with the moisture and finally produce hydrochloric acids also formed H2S. That is an approach of the metallic corrosion as explained in the Equation (5), Equation (6) and Equation (7).

$$
\begin{gathered}
\mathrm{CaCl}_{2}+\mathrm{H}_{2} \mathrm{O} \rightarrow \mathrm{CaO}+2 \mathrm{HCL} \\
2 \mathrm{HCL}+\mathrm{Fe} \rightarrow \mathrm{FeCl}_{2}+\mathrm{H}_{2} \\
\mathrm{FeCl}_{2}+\mathrm{H}_{2} \mathrm{~S} \rightarrow \mathrm{FeS}+2 \mathrm{HCl}
\end{gathered}
$$

According to the results there were found higher amounts of both elemental sulfur and active sulfur compounds in Das Blend crude oil than the Murban crude oil. Sulfur compounds consisted with some fraction or a functional group which can be reacted with metallic compounds and tend to be formed the corrosion usually called as the "sulfidation" Those compounds are known as active compounds including elemental sulfur, mercaptans and hydrogen sulfides although highly depended on the temperature. Mercaptans also identified as a corrosive compound which is having a formula of RSH. The typical temperature for a proper sulfidation process is nearly $2300 \mathrm{C}[2,8,9]$. The general chemical reaction of sulfidation is given in the Equation (8).

$$
8 \mathrm{Fe}+\mathrm{S} 8 \rightarrow 8 \mathrm{FeS}
$$

There found some higher corrosive strength from Das Blend crude oil than the Murban crude oil because it was composed higher amounts of sulfur, mercaptans and organic acids than Murban while higher amount of slats composed in Murban crude oil than Das Blend crude oil.

\subsection{Corrosion rates of metals}

According to the determinations of weight loss method the average corrosion rates of metal coupon are given in the Figure 2.

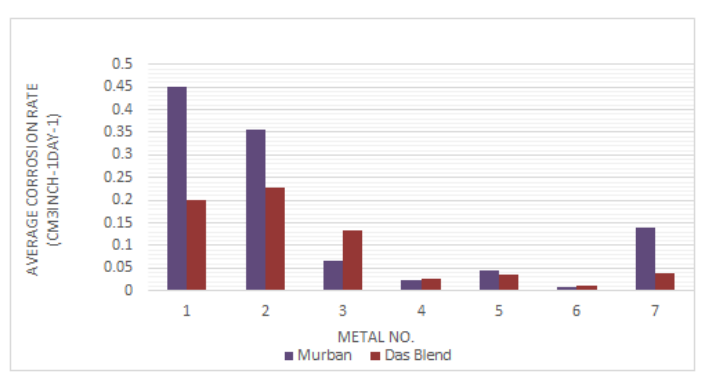

Figure 2. Corrosion rates of metals in both crude oils

According to the distribution of the corrosion rates there were observed relatively higher rates of corrosion from different three types of carbon steels and relatively lower corrosion rates in stainless steels including the least corrosion rates in both crude oils from 321-MN:1.4 304-MN:1.9 (Stainless Steel). Also the Monel metal showed moderate corrosion rates in both crude oils. When referring the chemical compositions of stainless steels those metals were composed at least 12 chromium with sufficient amount of nickel and also the 
combination of nickel and chromium tend to be formed much useful corrosive protection film on the relevant metal itself $[1,4,5,10]$. Therefore, the stainless steels showed relatively lower corrosion rates in both crude oil than the corrosion rates of other metals.

Regarding the effect of crude oils on the rate of corrosion in seven different types of ferrous metals there were found higher corrosion rates from four types of metals in Murban crude oil than the Das Blend crude oil since Das Blend was ahead in corrosive properties because of the requirement of higher temperature for a proper "sulfidation" process $[2,8,9]$.

The variations of the corrosion rate of each metal coupon with the exposure time accordance to both crude oils are given in the Figure 3.

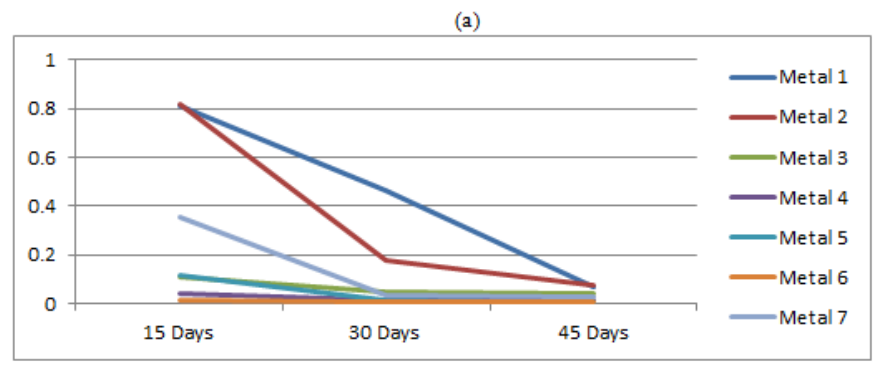

(b)

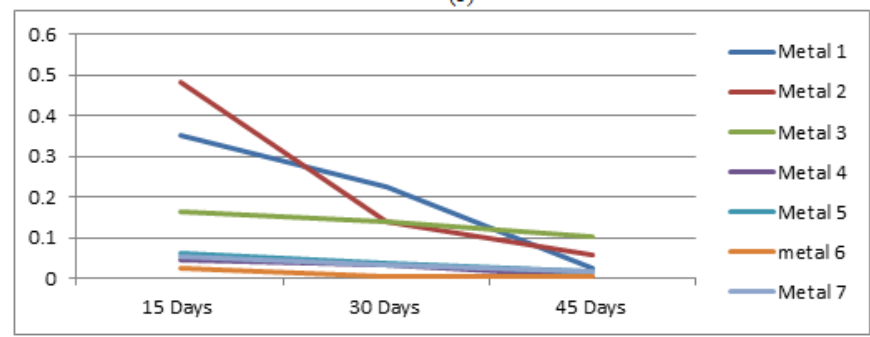

Figure 3. Variation of the corrosion rates of metals with the exposure time in (a) Murban and in (b) Das Blend

According to the above distribution there were identified the gradual reduction of the rate of corrosion in each metal coupon with the exposure time in front of the crude oils. Also there cannot be emphasized a recent sequence or series regarding the variation although it can be proved the inversely proportional relationship between the corrosion rate and the exposure time period by referring the above distribution [3].

\subsection{Microscopic Review}

According to the microscopic analysis there were identify some of distinguish properties of corrosion compounds based on their visible features foremost the color [4]. The important observations are highlighted in the Figure 4.

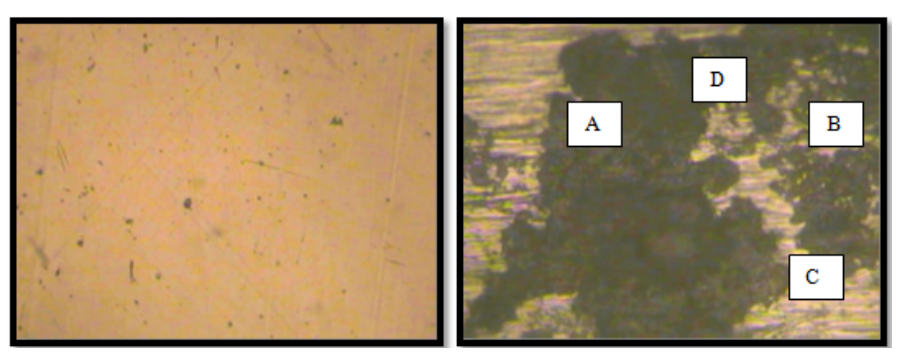

Figure 4. Corroded surface of 410-MN: 1.8 420- MN: 2.8 (Stainless Steel) in Murban

The optical features interpret some important corrosive compounds and observations which are explained the behaviors of the corrosion.

- Ferrous Sulfides 
- Corrosion Cracks

- Pitting Corrosion

- Trace Compounds

Some of special features of corrosion compounds and recent observation from the current research have been finalized in the Table 4 .

Table 4. Properties of corrosion compounds

\begin{tabular}{|c|c|c|}
\hline Compound & Appearances & Observations \\
\hline $\mathrm{FeS}$ & $\begin{array}{c}\text { Black, brownish black, property of powder, } \\
\text { pitting, cracks }\end{array}$ & Observed most of features in \\
\hline $\mathrm{Fe} \_2 \mathrm{O} \_3$ & Rusty color & Observed rarely \\
\hline Cus & Dark indigo/ dark blue & Unable to specify \\
\hline
\end{tabular}

According to the obtained results there were observed most of above features on most of metals and also there were observed corrosion cracks on most of stainless steels. By analyzing the specific properties of corrosive compounds there can be concluded the formation of FeS on the surfaces of stainless steels and carbon steel. Also there can be assumed that the formation of CuS on Monel metal surfaces although it's impossible to specify CuS along with the optical features.

\subsection{Decay of Metals}

During the corrosion rate analysis there were found some invisible weight loss from most of metal coupons apart from specific corrosion compounds. The major objective of the analysis of atomic absorption spectroscopy (AAS) was to investigate the decay of metals into crude oils. The obtained results for the AAS analysis are shown in the Figure 5.

(a)

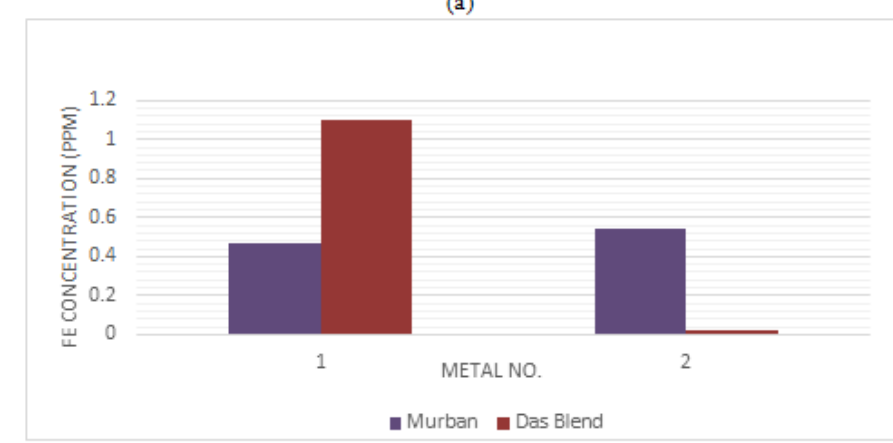

(b)

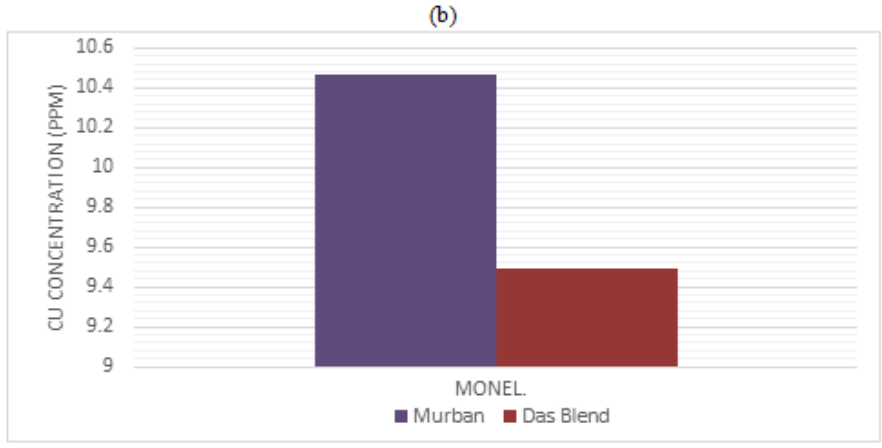

Figure 5. (a) Ferrous concentration and (b) copper concentration in crude oil samples

The results showed some considerable amount of ferrous in both Murban and Das Blend crude oil samples which were exposed to high carbon steels and medium carbon steels also found highest corrosion rates from such metals and simultaneously found some higher copper concentration in both crude oil samples which were exposed to Monel metal also it showed moderate corrosion rates. The corrosion compounds are tended to remove from the metal surfaces once it has been formed on the metal surface because of the repulsive and 
attractive forces in between successive electrons and protons [4]. The invisible weight loss of metals can be explained under this concept can be emphasized the mechanism of the decay of metals.

\subsection{Reduction of the Hardness in Metals}

The distribution of the variations between initial hardness and hardness after corroded has been shown in the Figure 6.

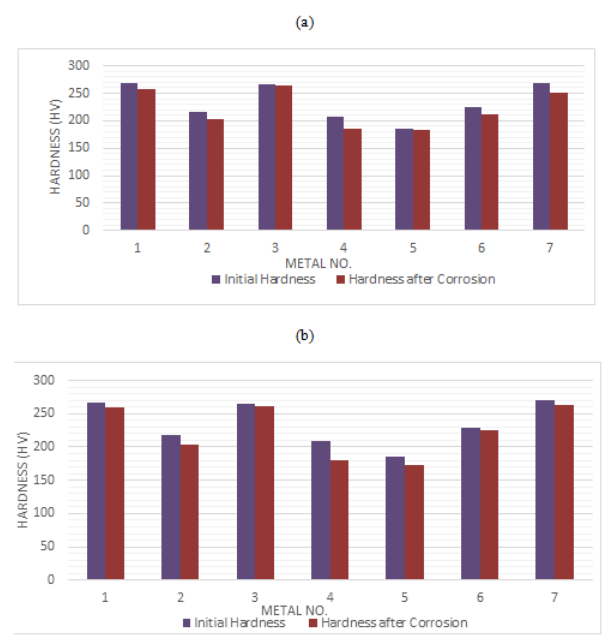

Figure 6. Variations of the initial hardness of metals in (a) Murban and in (b) Das Blend

There were identified slight reductions of the initial hardness of metal coupons due to the corrosion accordance to both crude oil even though unable to specify any relationship or any sequence regarding the variations of the hardness with respect to any crude oil or even any type of metal. The hardness of metals may be varied with the position where it will be tested and after the formation of corrosion compounds the stability of the metal surfaces will be reduced due to the tendency of removing those particular compounds from the metal surface [1,2]. According to the obtained results there can be concluded the formation of the corrosion compounds on each metal surface also proved the interaction between metals and crude oils.

\section{Conclusion}

According to the obtained results the least corrosion rates were found from 321-MN: 1.4 304-MN: 1.9 (Stainless Steel) in both crude oils while finding relatively corrosion rates from carbon steels and Monel as well. Because 321-MN: 1.4 304-MN: 1.9 (Stainless Steel) is composed 18 chromium and 8 nickel which is tend to create a stable corrosive protection layer on the metal surface itself. It was found higher corrosion rates of four types of metals in Murban crude oil while other three types were showing higher corrosion rates in Das Blend since Das Blend crude oil was composing higher amount of sulfur, mercaptans and organic acids although lower amount of salts than the Murban crude oil also it can be concluded the effect of salts is stronger than the overall effect of organic acids, sulfur and mercaptans at the room temperature. Apart from that there were identified black color corrosive compound, corrosion cracks and pitting corrosion accordance the microscopic analysis. Also found some significant ferrous concentrations in crude oil samples regarding carbon steels and significant amount of copper in crude oil samples regarding Monel since unable to find any amount of ferrous in crude oil samples regarding stainless steel. The slight reductions of the initial hardness of metal coupons were observed due to the corrosion eventually.

Author Contributions: All authors contributed equally to the writing of this paper. All authors read and approved the final manuscript.

Conflicts of Interest: "The authors declare no conflict of interest."

\section{References}

[1] Khana, O.P. (2009). Materials Science and Metallurgy. New Delhi: Dhanpet Rai and Sons Publication.

[2] Fahim, M. A., Al-Sahhaf, T. A., \& Elkilani, A. (2009). Fundamentals of petroleum refining. Elsevier. 
[3] Oparaodu, K. O., \& Okpokwasili, G. C. (2014). Comparison of percentage weight loss and corrosion rate trends in different metal coupons from two soil environments. International journal of environmental bioremediation $\mathcal{E}$ biodegradation, 2(5), 243-249.

[4] Callister, W. D. (2007). An introduction to materials science and engineering. John Wiley, New York, 1991$)$ p, 420.

[5] Davis, M. E., \& Davis, R. J. (2012). Fundamentals of chemical reaction engineering. Courier Corporation.

[6] Afaf, G. A. (2007). Corrosion Treatment of High TAN Crude (Doctoral dissertation, PhD. Thesis, University of Khartoum, Khartoum, Sudan).

[7] Badmos, A. Y., Ajimotakan, H. A., \& Emmanuel, E. O. (2009). Corrosion in petroleum pipelines. New York science journal, 2(5), 36-40.

[8] Bolton, W. (2013). Engineering materials technology. Elsevier.

[9] Speight, J. G. (2014). The chemistry and technology of petroleum. CRC press.

[10] Singh, R. (2006). Introduction to Basic Manufacturing Process and Engineering Workshop. New Delhi: New Age International Publication.

(C) 2019 by the authors; licensee PSRP, Lahore, Pakistan. This article is an open access article distributed under the terms and conditions of the Creative Commons Attribution (CC-BY) license (http://creativecommons.org/licenses/by/4.0/). 